\title{
Cyclic ST-segment elevation after primary percutaneous coronary intervention
}

\author{
W. P. J. Jansen
}

Accepted: 29 September 2020 / Published online: 9 October 2020

(C) The Author(s) 2020

A 44-year-old man was admitted for an inferior STelevation myocardial infarction (STEMI), for which he underwent successful primary percutaneous coronary intervention of the occluded right coronary artery (RCA). Several hours later, ST-segment monitoring revealed a strikingly regular pattern of intermittent inferior ST-elevation, confirmed by 12lead electrocardiography (Fig. 1a). Following sublingual administration of nitroglycerin, the ST-elevation completely resolved; however, it reoccurred after $1 \mathrm{~h}$ (Fig. 1b). Repeat angiography showed a patent RCA with Thrombolysis in Myocardial Infarction (TIMI) III flow. Intravenous nitrates and oral diltiazem were administered, after which the phenomenon did not reoccur.

Cyclic ST-elevation after acute coronary syndromes has been described previously [1]. I found one similar case of intermittent ST-elevation after NSTEMI, which was reversed by intravenous nitrates [2]. Several hypotheses have been postulated, including coronary vasospasm and platelet-mediated thrombus formation [3, 4]. Angiographic results and response to spasmolytic agents suggest a vasospastic phenomenon. The explanation for the strikingly cyclic pattern, however, remains to be elucidated.

Conflict of interest W.P.J. Jansen declares that he has no competing interests.

Open Access This article is licensed under a Creative Commons Attribution 4.0 International License, which permits use, sharing, adaptation, distribution and reproduction in any medium or format, as long as you give appropriate credit to the original author(s) and the source, provide a link to the Creative Commons licence, and indicate if changes were made. The images or other third party material in this article are included in the article's Creative Commons licence, unless indicated otherwise in a credit line to the material. If material is not included in the article's Creative Commons licence and your intended use is not permitted by statutory regulation or exceeds the permitted use, you will need to obtain permission directly from the copyright holder. To view a copy of this licence, visit http://creativecommons.org/licenses/by/4.0/.

\section{References}

1. Albertal M, Cura F, Krucoff MW, et al. Coronary cyclic flow variations following primary angioplasty is associated with poor short-term prognosis. Int JCardiol. 2008;130:220-6.

2. Azzarone M, Fasulo A, Leuzzi C, et al. Complete sustained reversalofcyclicST-segmentelevation (coronarycyclicflow variations) by low-dose intravenous nitroglycerin during acutecoronarysyndrome. JElectrocardiol. 2014;47:219-22.

3. Koiwaya Y, Torii S, Takeshita A, et al. Postinfarction angina caused by coronary artery spasm. Circulation. 1982;65:275-80.

4. Folts JD, Stamler JS, Loscalzo J. Intraveneous nitroglycerin infusion inhibits cyclic blood flow responses caused by periodic platelet thrombus formation in stenosed canine coronary arteries. Circulation. 1991;83:2122-7.
W. P. J. Jansen $(\bowtie)$

Department of Cardiology, Tergooi Hospital, Blaricum, The

Netherlands

wajansen@tergooi.nl 
Fig. 1 a Heart rate (HR) trend and ST-segment trend (left) showing repetitive STelevation with 14-minute intervals, without concomitant HR variation. Electrocardiography recordings (right) confirm ST-elevation in inferior leads. b Complete resolution of ST-elevations after application of sublingual nitrate spray, only to reoccur after $1 \mathrm{~h}$, in the same repetitive manner

b

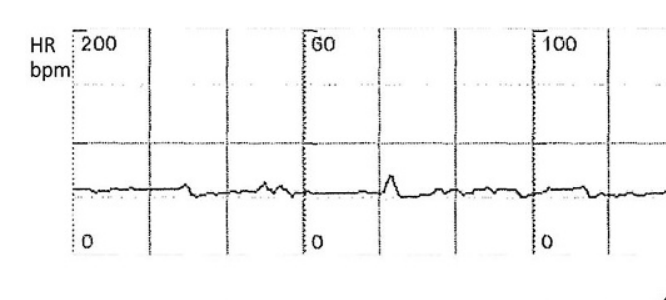

' L avR
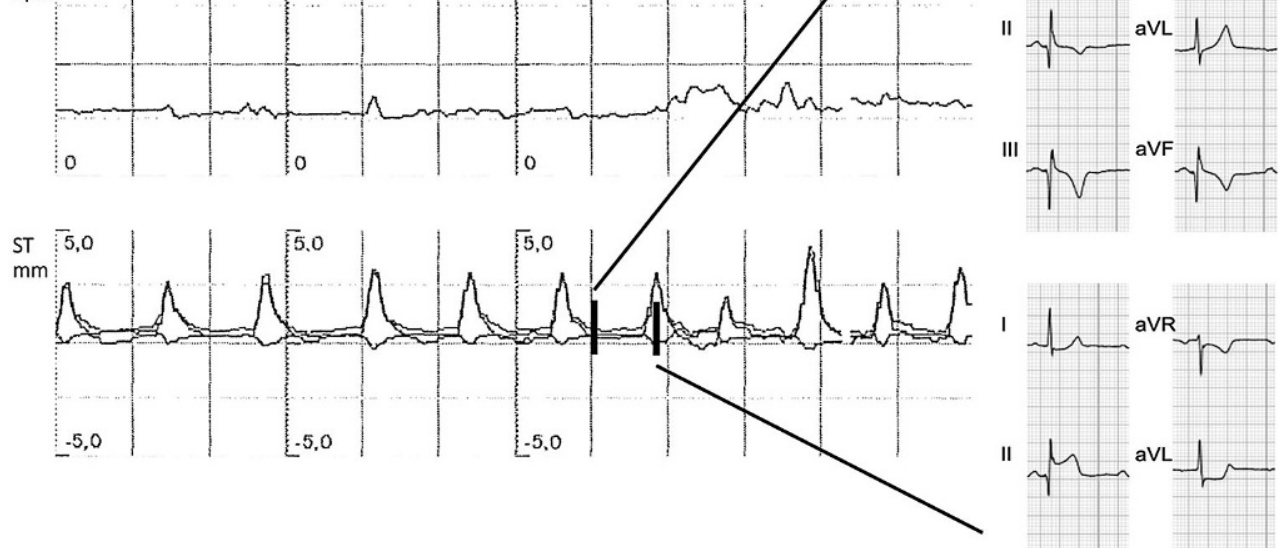

III

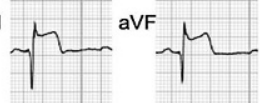

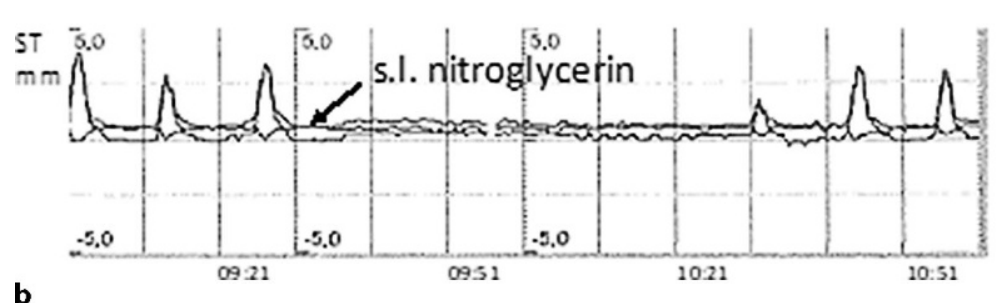

